\title{
Contemporary Strategies for Managing Cardiometabolic Risk Factors
}

STEPHEN N. DAVIS, MD, FRCP

\begin{abstract}
OBJECTIVE: To review the metabolic syndrome as defined by the 2001 Expert Panel on Detection, Evaluation, and Treatment of High Blood Cholesterol in Adults (ATP III) and its modifiable risk factors and to review currently available treatment modalities.

SUMMARY: Metabolic syndrome, although still controversial, is a growing concern. Most definitions include elevated blood pressure, smoking, inflammation, insulin resistance, abdominal adiposity, elevated blood glucose, and atherogenic dyslipidemia as modifiable risk factors. Some researchers believe that additional signs of inflammation such as plasminogen activator inhibitor-1 and C-reactive protein should be added to this list. Current treatment options include lifestyle changes (diet and exercise), pharmacotherapy, and bariatric surgery. The endocannabinoid system appears to play a key role in metabolism and weight gain. The investigational agent rimonabant is a cannabinoid receptor type 1 blocker that has been employed in numerous trials involving more than 6,500 patients. It has led to significant weight loss, reduced central fat, and improved glycemic and lipid profiles.
\end{abstract}

KEYWORDS: Metabolic syndrome, Adipose tissue, ATP III guidelines, C-reactive protein, Rimonabant

J Manag Care Pharm, 2006;12(1)(suppl):S4-S9
$\mathrm{M}$ etabolic syndrome has several definitions, some of which remain controversial. The American Diabetes Association (ADA) and the European Association for the Study of Diabetes have discussed doing away with this term. ${ }^{1}$ The controversy has plagued this symptom constellation for decades; in the 1980s, Gerald Reaven called it "Syndrome X,"” prompting others to ask, "Is it real?" In the 1990s, we referred to "the insulin resistance syndrome," or resistance to insulin-stimulated glucose uptake. A symptom constellation that transcends simple insulin resistance, however, occurs with great frequency around the world, and although some organizations question whether an actual syndrome exists, even they agree that these symptoms must be addressed aggressively and in concert. Addressing only one of the symptoms is a disservice to patients. Metabolic syndrome's importance rests on a simple fact: it is associated with a 2- to 4-fold increase in cardiovascular morbidity and stroke. ${ }^{4}$

\section{Many Definitions}

Two factors in cardiovascular risk are the underpinnings of the tremendous upsurge in diabetes and the metabolic syndrome: lack of exercise and ample, available, palatable food. The term "cardiometabolic risk" describes the increased risk of cardiovascular and/or metabolic morbidity resulting from a cluster of risk factors. The 2001 Expert Panel on Detection, Evaluation, and Treatment of High Blood Cholesterol in Adults (ATP III of the National Cholesterol Education Program [NCEP]) identified a cluster of modifiable risk factors predisposing individuals to cardiovascular and metabolic disease (and type 2 diabetes, which is related). The ATP III list includes elevated blood pressure, smoking, insulin resistance, abdominal adiposity, and elevated blood glucose. It also includes atherogenic dyslipidemia, which may include elevated triglycerides, and/or low high-density lipoprotein cholesterol (HDL-C). Together, these factors increase the risk for cardiovascular and metabolic conditions such as myocardial infarction (MI), stroke, and diabetes. ${ }^{5}$

Risk factors alone are one issue, but when they occur in a pattern that is indicative of a disease, many experts begin to describe them as a syndrome. Recognizing that the presence of cardiometabolic risk factors increases morbidity and mortality, the World Health Organization, International Diabetes Federation, and the NCEP's ATP III have issued practical guidelines identifying this constellation of risk factors as "metabolic syndrome." Their definitions differ, and there is currently no consensus, although most definitions are similar. ${ }^{5}$ Table 1 presents the ATP III guidelines for the clinical identification of metabolic syndrome. Note that they designate gender-specific cutoffs for low HDL and high waist circumference. A diagnosis of metabolic syndrome is made when 3 or more of these risk determinants are present. ${ }^{5}$

\section{Other Factors?}

Insulin resistance is a driver of cardiometabolic risk. ${ }^{1}$ Insulin 
resistance is not solely insulin's inability to drive glucose into cells. It is a more fundamental problem that remains poorly understood. One might expect that 2 people who eat a candy bar would gain the same amount of weight. In the insulin-resistant individual, however, more energy may be stored as triglycerides in adipose tissue than will be metabolized. The net effect will be that the insulin-resistant individual will have a greater propensity to gain weight than the normal metabolizer.

Inflammation is an additional concern. One inflammatory marker, plasminogen activator inhibitor-1 (PAI-1), is involved in a major clotting mechanism. It is closely associated with cardiovascular disease, and, in fact, when added to other cardiometabolic risk factors, may work synergistically. Although, currently, the best predictor of type 2 diabetes is elevated fasting blood glucose or elevated glucose postchallenge, some researchers believe that, in the future, an elevated PAI-1 may also become an excellent tool to predict type 2 diabetes. ${ }^{6}$

Elevated blood glucose also represents a risk and may be a mechanism for cardiovascular disease. ${ }^{7}$ Two large multicenter studies are currently underway to determine the extent to which hyperglycemia is an independent risk factor for myocardial infarction and peripheral vascular disease in individuals with type 2 diabetes. The Action to Control Cardiovascular Risk in Diabetes (ACCORD) study is examining the possibility of preventing major cardiovascular events (heart attack, stroke, or cardiovascular death) in adults with type 2 diabetes mellitus using intensive glycemic control, intensive blood pressure control, and intensive lipid management. This study began enrollment in September 1999, and completion is expected in September 2010. The primary objective of the Veterans Affairs Diabetes Trial (VADT) is assessment of intensive glycemic treatment on cardiovascular events. Microangiopathy, quality of life, and cost-effectiveness are additional objectives being scrutinized. This study is of great interest because the participants come from an elderly population that has high rates of obesity and advanced complications. Enrolling since December 2000, 1,700 men and women with previously uncontrolled diabetes will be maintained on insulin or maximum doses of oral agents at 20 Veterans Affairs medical centers. Accrual is expected to take 2 years, with follow-up for 5 to 7 years.

C-reactive protein's (CRP's) contribution to disease development is unclear but appears to be tightly correlated with cardiovascular disease and diabetes. The statin drugs primarily used to lower low-density lipoprotein cholesterol (LDL-C) also lower CRP levels. In a study of 3,745 patients treated with either pravastatin or atorvastatin, researchers found that when statin therapy resulted in LDL cholesterol levels of $<70 \mathrm{mg} / \mathrm{dL}$ or CRP levels of $<2 \mathrm{mg} / \mathrm{L}$, patients had fewer cardiovascular events (2.4 events per 100 person-years) than with higher levels (3.1 events per 100 person-years). After 4 years of statin therapy, patients who had LDL-C levels of $<70 \mathrm{mg} / \mathrm{dL}$ and CRP levels of $<1 \mathrm{mg} / \mathrm{L}$ had the lowest rate of recurrent events (1.9 events per 100 person-years). They concluded that patients who have

\section{TABLE 1 Metabolic Syndrome}

ATP III defines metabolic syndrome as consisting of any 3 or more of the following risk factors:

Triglycerides

HDL-C

Men

Women

Blood pressure

Fasting glucose

Waist circumference

Men

Women

$\geq 150 \mathrm{mg} / \mathrm{dL}$

$<40 \mathrm{mg} / \mathrm{dL}$

$<50 \mathrm{mg} / \mathrm{dL}$

$\geq 130 \mathrm{~mm} \mathrm{Hg} / 85 \mathrm{~mm} \mathrm{Hg}$

$\geq 110 \mathrm{mg} / \mathrm{dL}^{*}$

$>40$ inches

$>35$ inches

Note: The American Diabetes Association now defines fasting glucose levels of 100 to $125 \mathrm{mg} / \mathrm{dL}$ as impaired fasting glucose, and the American Heart Association has suggested lowering the cutoff to $<100 \mathrm{mg} / \mathrm{dL}$.

ATP III = Expert Panel on Detection, Evaluation, and Treatment of High Blood

Cholesterol in Adults (Adult Treatment Panel III); HDL-C=high-density lipoprotein cholesterol.

low CRP levels have better clinical outcomes than those with higher CRP levels, regardless of the resultant LDL-C levels. ${ }^{8}$ An elevated CRP level provides some prognostic information for the risk of metabolic syndrome. It is also a predictor for diabetes. Some experts have suggested adding elevated CRP to the list of components of the metabolic syndrome.

\section{Prevalence}

Ford et al. applied the ATP III criteria described in Table 1 to 8,814 participants in the Third National Health and Nutrition Examination Survey (1988-1994), a cross-sectional health survey of a nationally representative sample of the noninstitutionalized civilian U.S. population. They estimated the prevalence of metabolic syndrome to be approximately $24 \%$ of the total U.S. adult population of 196 million, or 47 million adults. ${ }^{9}$ The Centers for Disease Control and Prevention's 2005 data indicate that around 21 million Americans (or 7\% of the population) have diabetes, and an additional 41 million people have impaired fasting glucose (sometimes called prediabetes, or a fasting glucose between $100 \mathrm{mg} / \mathrm{dL}$ and $125 \mathrm{mg} / \mathrm{dL}){ }^{10}$

A recent National Institutes of Health (NIH) study reported that people in the United States with impaired glucose tolerance (IGT) may develop diabetes at a rate of about $11 \%$ annually. ${ }^{11}$ Given the prevalence of IGT, the prevalence of diabetes may double within 10 years. Roughly $42 \%$ of Americans have elevated fasting glucose levels. When diabetes begins, up to $25 \%$ of people have normal fasting glucose levels but elevated postprandial glucose levels. ${ }^{7}$

\section{Adipose Tissue as an Organ}

Until just a few years ago, it was widely believed that adipose tissue was a fairly inert means of storing excess calories. Now, however, we have learned that adipose tissue is an active 
FIGURE 1 Adipose Tissue: Subcutaneous vs Visceral

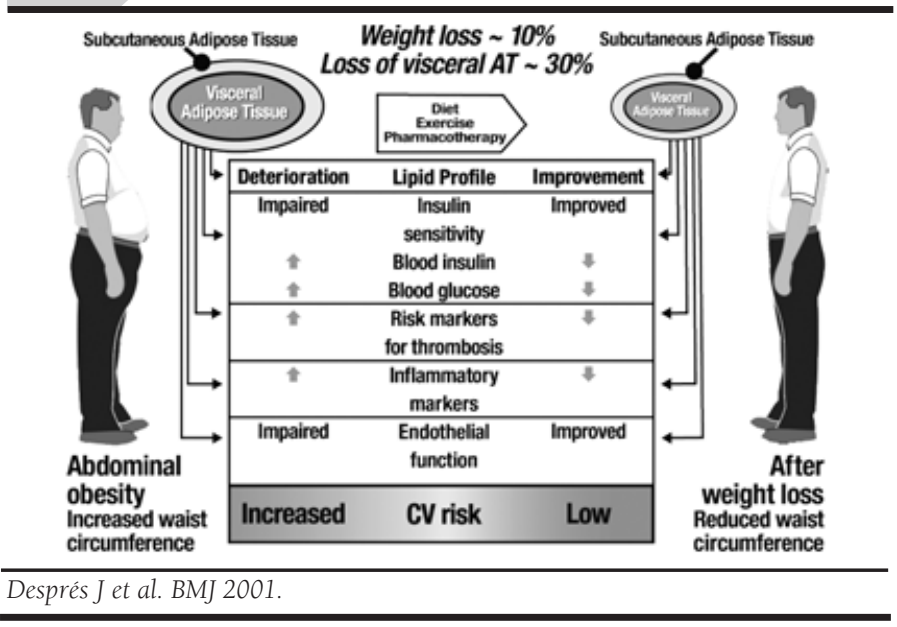

TABLE 2 A Guide to Selecting Treatment: NIH Guidelines

\begin{tabular}{|c|c|c|c|c|c|}
\hline \multirow[b]{2}{*}{ Treatment } & \multicolumn{5}{|c|}{ BMI Category } \\
\hline & $25-26.9$ & $27-29.9$ & $30-34.9$ & $35-39.9$ & $\geq 40$ \\
\hline $\begin{array}{l}\text { Diet, physical } \\
\text { activity, } \\
\text { behavior }\end{array}$ & $\begin{array}{c}\text { Yes with } \\
\text { comorbidities }\end{array}$ & $\begin{array}{c}\text { Yes with } \\
\text { comorbidities }\end{array}$ & Yes & Yes & Yes \\
\hline $\begin{array}{l}\text { Pharmaco- } \\
\text { therapy }\end{array}$ & 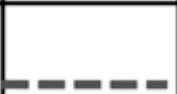 & $\begin{array}{c}\text { Yes with } \\
\text { comorbidities }\end{array}$ & Yes & Yes & Yes \\
\hline $\begin{array}{l}\text { Weight-loss } \\
\text { surgery }\end{array}$ & & & & $\begin{array}{c}\text { Yes with } \\
\text { comorbidities }\end{array}$ & Yes \\
\hline- & $1--=-$ & $--=-$ & $=-$ & & \\
\hline
\end{tabular}

* Yes alone indicates that the treatment is indicated regardless of the presence or absence of comorbidities. The solid arrow signifies the point at which therapy is initiated.

NIH/NHLBI/NAASO; NIH Publication No. 00-4084. October 2000. endocrine organ. Adipose tissue releases fatty acids, which can cause metabolic insulin resistance; it is also associated with higher levels of circulating CRP (a marker of chronic subclinical inflammation) and lower levels of adiponectin. ${ }^{12}$ Adiponectin, an adipose tissue-specific circulating protein, improves insulin sensitivity and reduces insulin resistance. ${ }^{13}$ Obese subjects and subjects with type 2 diabetes have decreased adiponectin plasma levels, ${ }^{14}$ reduced HDL-C, high triglycerides, and small dense LDL-C. (The size of LDL-C is important. Larger LDL-C particles, which appear fluffier (more buovant) under the microscope, are less atherogenic than the highly oxidized small dense form of LDL-C. ${ }^{15}$ ) Increased adiponectin levels are associated with a reduction in body weight ${ }^{16}$ and reduced levels of insulin, leading to improved insulin sensitivity. ${ }^{17}$ Drugs like metformin and the thiazolidinediones increase adiponectin.

Computed tomography (CT) scan or magnetic resonance imaging (MRI) can establish exact adipose tissue location and are considered the gold standards for doing so. Researchers observed in 1947 that women tend to gain weight in 2 separate places: in their hips and centrally (abdominally). Men tend to gain weight abdominally. ${ }^{18}$ For several decades, clinicians have embraced an easy description of the differences: "apples" versus "pears." Appleshaped people gain weight centrally, while pear-shaped people gain weight toward their hips. ${ }^{19-21}$ Growing circumstantial evidence indicates that visceral (central or apple) fat detected by CT or MRI correlates more closely with metabolic and cardiovascular complications of obesity, increasing diabetes risk up to 10-fold.22-26

Studies have investigated whether removing fat using liposuction might lower cardiometabolic risk. Klein et al. removed 28\% to $44 \%$ of subcutaneous adipose tissue in 15 obese women. Liposuction did not significantly alter muscle, liver, or adipose insulin sensitivity, nor did it significantly alter CRP, interleukin-6, tumor necrosis factor-alpha, or adiponectin plasma concentrations. Similarly, blood pressure, plasma glucose, insulin, and lipid concentrations did not change. ${ }^{27}$ Fat located in the visceral cavity (visceral adiposity), and especially fat located in the liver, is metabolically more active than subcutaneous adipose tissue. The role played by intrahepatic fat accumulation is a major research focus in the gastrointestinal, diabetes, and cardiovascular fields. Researchers postulate that hepatic adipose tissue (fatty liver) may drive increased glucose production, and be part of a gut-central nervous system (CNS) cycle that can regulate metabolism. ${ }^{28}$ Thus, the quick fix of simply removing fat surgically is not a solution.

Figure 1 demonstrates the importance of adipose tissue's location either viscerally or subcutaneously. Abdominally obese individuals who lose body weight tend to experience preferential or selective mobilization of visceral adipose tissue. A reduction of $5 \%$ to $10 \%$ of body weight can lead to simultaneous improvement in all metabolic markers of coronary heart disease risk. As depicted in the figure, a weight loss of about $10 \%$ translates into a visceral adipose tissue loss approximating 30\%, which elicits improvement in all metabolic parameters. Insulin resistance is reduced, insulin and blood glucose move downward toward normal levels, risk markers for thrombosis and inflammation improve, and endothelial function improves. ${ }^{29}$

\section{Steps to Improved Care}

Patients with metabolic syndrome present with a complicated set of needs. Different practitioners will address cardiometabolic risk factors differently. Endocrinologists tend to treat blood glucose, blood pressure, and lipids together. Busy general practitioners sometimes have to split risk-factor treatment, addressing blood pressure, glucose, and lipids at separate visits. Generally, the steps in a good plan include identifying at-risk patients (as discussed above), encouraging behavior modification, and then using pharmacotherapy. 
NIH has published guidelines to help clinicians identify appropriate steps when patients with metabolic syndrome (see Table 2) present for care. Certain lifestyle changes are always appropriate. When body mass index (BMI) is above 27, pharmacologic agents may be indicated if comorbidities are present; if patients are morbidly obese ( $>100$ pounds overweight or have a BMI $>35$ and at least 2 comorbidities), bariatric surgery is an option..$^{30}$ This latter option is used more frequently; the number of gastric bypass surgeries climbed more than 600\% from 1993 to 2003, when 103,000 Americans underwent this procedure. ${ }^{31}$ Its complications include infection, hernia, gall stones, and malabsorption syndromes.

Exercise continues to be a highly recommended and very effective intervention. In recent years, recommendations are more likely to refer to "physical activity" than exercise, stressing that the benefits of repeated brief periods of as little as 10 minutes of activity during the day are cumulative. In 1996, the U.S. Surgeon General recommended that most American adults need a minimum of 30 minutes of physical activity most days of the week. ${ }^{32}$ Yet, approximately $25 \%$ of the population does not exercise at all..$^{33}$ A September 2002 Institute of Medicine (IOM) report more than doubled the time recommended to at least 60 minutes of moderately intense physical activity—such as brisk walking — every day. It recommends twice that amount if the goal is weight loss. ${ }^{34}$

The 1996 recommendation was based on research showing that 30 minutes of physical activity most days of the week could reduce the risk of many chronic diseases. The IOM based its recommendation on evidence showing that 30 minutes of activity most days of the week may be insufficient for most people to maintain an ideal weight and achieve maximum health benefits. These recommendations acknowledge that Americans consume more calories than ever before, and are becoming heavier. Clearly, public health and public opinion must change, and the best place to initiate the change and establish exercise as a habit is among children.

Numerous drug therapies are available for the constellation of risk factors described herein. These would include

- the antiobesity agents: sibutramine (an anorexiant that may cause hypertension and increased sympathetic activity) and orlistat (a lipase inhibitor that often causes a gastrointestinal malabsorption syndrome); use of either agent usually results in a moderate weight loss of approximately $4 \%$ to $8.5 \%$ of body weight at 2 years of treatment ${ }^{35}$;

- the antihypertensive agents, noting that some of the newer antihypertensive agents have pleotropic effects (simultaneous effects on multiple systems);

- the oral antidiabetic agents, many of which have dose- and compliance-limiting side effects;

- insulin and the new injectable antidiabetic agents: exenatide and pramlintide acetate;

- lipid modifiers;

- and antiplatelet agents.

\section{FIGURE 2 Effects of ECS Overactivity}

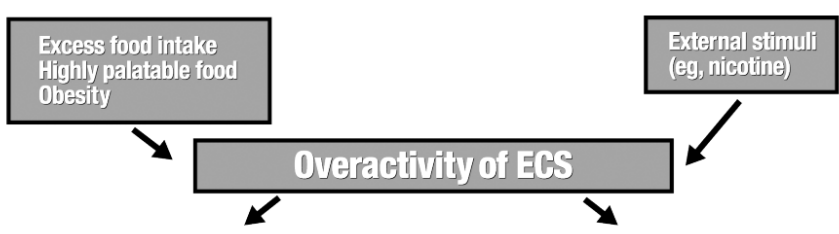

BPAIN

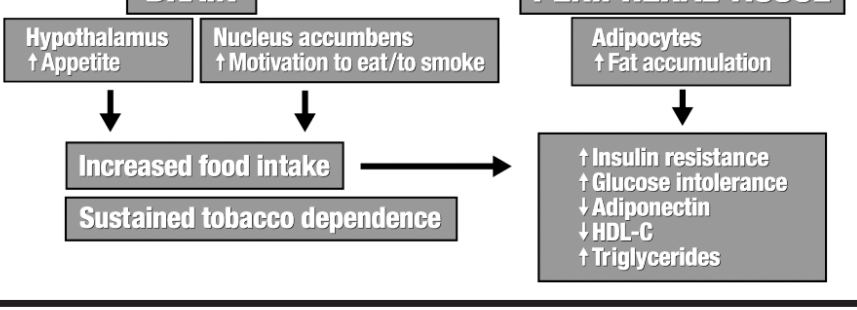

No specific "metabolic" anti-inflammatory agent has been developed or approved by the U.S. Food and Drug Administration yet. These therapies and interventions are not completely effective against metabolic syndrome nor are they always easy to comply with—with or without side effects. Something new is needed.

\section{Something New}

Since dietary changes and exercise appear to be insufficient to blunt the increase in obesity, another intervention is needed, perhaps one that would address the problem at both the CNS and peripheral target organ level. The endocannabinoid system (ECS) is a very important neuromodulatory signaling system. ECS plays a major role in many important physiologic processes, including energy homeostasis, regulation of body weight and metabolic processes, and motivational behaviors. Unfortunately, excessive food, especially palatable food, increases ECS activity and subsequently increases fat accumulation.

Cannabinoid receptors are distributed throughout the brain and body, with 2 types of G-protein-coupled cannabinoid receptors. Cannabinoid receptor type $1(\mathrm{CB} 1)$ is expressed predominantly in the central and peripheral nervous system, while cannabinoid receptor type 2 (CB2) is present almost exclusively in immune cells. ${ }^{36}$ Besides the well-known exogenous phytocannabinoids of the cannabis plant, endogenous cannabinoid ligands work very actively at these receptors and are cleared almost instantaneously. These endocannabinoids, derivatives of arachidonic acid, are produced as needed by cleavage of membrane lipid precursors (much like prostaglandin is)..$^{37}$ They play an important part in everyday physiology. The effects of ECS overactivity are presented in Figure 2. A CB1 blockade produces a lean phenotype in animals, with resistance to diet-induced obesity and associated dyslipidemia. 
Rimonabant is a new selective CB1 blocker. It has been studied in more than 6,500 patients in multicenter international studies in the United States and Europe. The Rimonabant in Obesity (RIO)Europe study assessed rimonabant's effect on body weight and cardiovascular risk factors in 1,509 overweight or obese patients. Participants had BMIs of $\geq 30 \mathrm{~kg} / \mathrm{m}^{2}$ or BMIs $>27 \mathrm{~kg} / \mathrm{m}^{2}$ with treated or untreated dyslipidemia, hypertension, or both. They were randomized to receive double-blind treatment with placebo, $5 \mathrm{mg}$ rimonabant, or $20 \mathrm{mg}$ rimonabant once daily. They followed a mild hypocaloric diet ( $600 \mathrm{k} \mathrm{cal} /$ day deficit) for 1 year. Weight loss was significantly greater in patients treated with rimonabant $5 \mathrm{mg}$ (mean loss of $3.4 \mathrm{~kg}$ [SD 5.7]; $P=0.002$ vs. placebo) and $20 \mathrm{mg}$ (mean loss of $6.6 \mathrm{~kg}$ [SD 7.2]; $P<0.001$ vs. placebo) compared with placebo (mean loss of $1.8 \mathrm{~kg}$ [SD 6.4]). Patients treated with rimonabant $20 \mathrm{mg}$ were significantly more likely to lose 5\% of their body weight than those treated with placebo. Compared with placebo, rimonabant $20 \mathrm{mg}$ was associated with significantly greater improvements in waist circumference, HDL-C (increases of approximately 25\%), triglycerides (decreases of $18 \%)$, insulin resistance, and prevalence of metabolic syndrome. ${ }^{37}$

Study participants in the rimonabant $20 \mathrm{mg}$ group were more likely to experience adverse events leading to discontinuation than those in the rimonabant $5 \mathrm{mg}$ and placebo groups. Common adverse events included nausea, dizziness, arthralgia and diarrhea, events that were generally mild to moderate in intensity. They also tended to be transient, occurring primarily during the first months of treatment. Although there were concerns that this centrally acting drug may cause psychiatric or nervous system adverse events, the incidence of these was generally low; however, discontinuation rates due to anxiety, depression, and nausea were slightly higher than placebo. ${ }^{38}$

Clearly, weight loss alone improves cardiovascular risk factors, and it would be important to tease out effects of treatment unrelated to weight loss. In the rimonabant trials, researchers were able to elucidate effects in excess of those related to weight loss because active treatment was compared with control. This allowed covariance analysis to test whether rimonabant treatment affected insulin resistance beyond the effect of greater weight loss produced by rimonabant. After adjustment for the differences between groups in weight loss, rimonabant's effect on both fasting insulin and estimated insulin resistance was found to be significant. Roughly half of the change in both variables could be attributed to weight loss and half of the improvement in insulin resistance was independent of rimonabant-induced weight loss. Rimonabant's peripheral and central effects seemed to influence risk factors positively. ${ }^{39}$

With each $1 \mathrm{mg} / \mathrm{dL}$ increase in HDL-C, cardiovascular risk and mortality falls $2 \% .^{40}$ Thus, rimonabant's effect on HDL-C is an important finding, considering that the prevalence of cardiovascular risk has increased 30\% in dyslipidemic patients in the last 10 years. ${ }^{41}$ Diabetes-related death from cardiovascular disease is increasing and expected to continue increasing unless effective interventions are found. Other modalities, such as exercise, can improve HDL-C, but this lifestyle change is a challenge for patients. Some treatment modalities may actually aggravate metabolic syndrome. Niacin has been used as a lipid modifier, for example, but at dosages exceeding 2 grams per day, insulin resistance increases. ${ }^{42}$

Another recently published RIO study, RIO-Lipids, examined changes in leptin and adiponectin. ${ }^{43}$ Study investigators found that if fat mass diminishes pursuant to treatment with rimonabant, leptin levels will fall and adiponectin levels, which improve insulin sensitivity, will rise. CRP, an important surrogate marker for inflammation, also tends to fall, reflecting a reduction in inflammation. ${ }^{44}$ Based on the results of the RIO-North America study, nondiabetic individuals with metabolic syndrome who were treated with rimonabant for 2 years experienced a 35\% reduction in metabolic syndrome while, among diabetics, the reduction was 19\%. ${ }^{39}$

The latest RIO study to report was the RIO-Diabetes study, which found that patients who received $20 \mathrm{mg}$ of rimonabant had a reduction of glycosylated hemoglobin (Alc) of $0.6 \%$ from baseline levels of $7.3 \%$, and weight and waist circumference were reduced 11.7 pounds and 2 inches, respectively, compared with those taking placebo. The mean difference between rimonabant and placebo was that rimonabant-treated patients lost a mean difference of 8.6 pounds more than those treated with placebo, with each 2.2 pounds corresponding to 0.4 inches of waist circumference loss. HDL-C and triglyceride levels were also similarly significantly improved compared with those found in RIO-Europe. Future studies may support use of rimonabant for the spectrum problems related to diabetes, or possibly to delay its onset. $^{45}$

\section{Summary}

Despite extensive medical advances in risk management, patients still experience cardiovascular events and develop type 2 diabetes. Current treatment paradigms tend to treat only a single element of the constellation of risk factors, for example, dyslipidemia, or glucose, or abdominal adiposity, or hypertension, but new therapeutic advances including the $\mathrm{CB} 1$ receptor blocker, rimonabant, combined with a hypocaloric diet, may reduce cardiometabolic risk and may sustain health benefits. If rimonabant in combination with other weight-loss interventions is shown to produce significant weight loss, it may eliminate the need for many bariatric surgeries.

\section{DISCLOSURES}

This article is based on the proceedings of a symposium held on October 7 , 2005, at the Academy of Managed Care Pharmacy's 2005 Educational Conference in Nashville, Tennessee, which was sponsored by the Benefit Design Institute and was supported through an educational grant from sanofiaventis. The author received an honorarium from sanofi-aventis for participation in the symposium. He has received grants from sanofi-aventis, Bayer, and Eli Lilly and Company. He discloses no potential bias or conflict of interest relating to this article. 


\section{REFERENCES}

1. American Diabetes Association. Is the metabolic syndrome really a syndrome? Available at: http://www.diabetes.org/diabetes-research/summaries/ ada-easd-metabolic-syndrome.jsp. Accessed November 4, 2005.

2. Reaven GM. Banting lecture 1988. Role of insulin resistance in human disease. Diabetes. 1988;37:1595-1607.

3. Neel JV, Julius S, Weder A, Yamada M, Kardia SL, Haviland MB. Syndrome $\mathrm{X}$ : is it for real? Genet Epidemiol. 1998;15:19-32.

4. Levantesi G, Macchia A, Marfisi R, et al; GISSI-Prevenzione Investigators. Metabolic syndrome and risk of cardiovascular events after myocardial infarction. J Am Coll Cardiol. 2005;46:277-83.

5. Executive Summary of The Third Report of The National Cholesterol Education Program (NCEP) Expert Panel on Detection, Evaluation, and Treatment of High Blood Cholesterol in Adults (Adult Treatment Panel III). JAMA. 2001;285:2486-97.

6. Festa A, D’Agostino R, Tracy RP, Haffner SM, Insulin Resistance Atherosclerosis Study. Elevated levels of acute-phase proteins and plasminogen activator inhibitor-1 predict the development of type 2 diabetes: the insulin resistance atherosclerosis study. Diabetes. 2002;51:1131-37.

7. Beisswenger P, Heine RJ, Leiter LA, Moses A, Tuomilehto J. Prandial glucose regulation in the glucose triad: emerging evidence and insights. Endocrine. 2004;25:195-202.

8. Ridker PM, Cannon CP, Morrow D, et al; Pravastatin or Atorvastatin Evaluation and Infection Therapy-Thrombolysis in Myocardial Infarction 22 (PROVE IT-TIMI 22) Investigators. C-reactive protein levels and outcomes after statin therapy. N Engl J Med. 2005;352:20-28.

9. Ford ES, Giles WH, Dietz WH. Prevalence of the metabolic syndrome among US adults: findings from the third National Health and Nutrition Examination Survey. JAMA. 2002;287:356-59.

10. Centers for Disease Control and Prevention. 2005 national diabetes fact sheet. Available at: http://www.cdc.gov/diabetes/pubs/factsheet05.htm. Accessed November 1, 2005.

11. Knowler WC, Barrett-Connor E, Fowler SE, et al; Diabetes Prevention Program Research Group. Reduction in the incidence of type 2 diabetes with lifestyle intervention or metformin. N Engl J Med. 2002;346:393-403.

12. Yamauchi T, Kamon J, Minokoshi Y, et al. Adiponectin stimulates glucose utilization and fatty-acid oxidation by activating AMP-activated protein kinase. Nat Med. 2002;8:1288-95.

13. Berg AH, Combs TP, Du X, Brownlee M, Scherer PE. The adipocyte-secreted protein Acrp30 enhances hepatic insulin action. Nat Med. 2001;7:947-53.

14. Weyer C, Funahashi T, Tanaka S, et al. Hypoadiponectinemia in obesity and type 2 diabetes: close association with insulin resistance and hyperinsulinemia. J Clin Endocrinol Metab. 2001;86:1930-35.

15. Matsubara M, Maruoka S, Katayose S. Decreased plasma adiponectin concentrations in women with dyslipidemia. J Clin Endocrinol Metab. 2002;87:2764-69.

16. Fruebis J, Tsao TS, Javorschi S, et al. Proteolytic cleavage product of $30-\mathrm{kDa}$ adipocyte complement-related protein increases fatty acid oxidation in muscle and causes weight loss in mice. Proc Natl Acad Sci USA. 2001;98:2005-10.

17. Chandran M, Phillips SA, Ciaraldi T, Henry RR. Adiponectin: more than just another fat cell hormone? Diabetes Care. 2003;26:2442-50.

18. Vague J. La differénciation sexuelle, facteur determinant des formes de l'obésité. (Sexual differentiation as a factor determining the forms of obesity.) Presse Méd. 1947;55:339-40 [in French].

19. Lafontan M, Berlan M. Do regional differences in adipocyte biology provide new pathophysiological insights? Trends Pharmacol Sci. 2003;24:276-83. 20. Moller R, Tafeit TE, Sudi TK, Reibnegger G. Quantifying the "appleness" or "pearness" of the human body by subcutaneous adipose tissue distribution. Ann Hum Biol. 2000;27:47-55.

21 . Wingard DL. Sex differences and coronary heart disease. A case of comparing apples and pears? Circulation. 1990;81:1710-12.

22. Lapidus L, Bengtsson C, Larsson B, Pennert K, Rybo E, Sjöström L. Distribution of adipose tissue and risk of cardiovascular disease and death: a 12-year follow-up of participants in the population study of women in Gothenburg, Sweden. BMJ (Clin Res Ed). 1984;289:1257-61.
23. Stokes III J, Garrison RJ, Kannel WB. The independent contributions of various indices of obesity to the 22-year incidence of coronary heart disease: the Framingham Heart Study. In: Vague J, Björntorp P, Guy-Grand B, RebufféScrive M, Vague P (eds). Metabolic Complications of Human Obesities. Amsterdam: Elsevier Science Publishers; 1985:49-57.

24. Ducimetière P, Richard J, Cambien F. The pattern of subcutaneous fat distribution in middle-aged men and risk of coronary heart disease: the Paris Prospective Study. Int J Obes. 1986;10:229-40.

25. Donahue RP, Abbott RD, Bloom E, Reed DM, Yano K. Central obesity and coronary heart disease in men. Lancet. 1987;1:821-24.

26. Ohlson LO, Larsson B, Svärdsudd K, et al. The influence of body fat distribution on the incidence of diabetes mellitus- 13.5 years of follow-up of the participants in the study of men born in 1913. Diabetes. 1985;34:1055-58.

27. Klein S, Fontana L, Young VL, et al. Absence of an effect of liposuction on insulin action and risk factors for coronary heart disease. N Engl J Med. 2004; 350:2549-57.

28. Wajchenberg BL. Subcutaneous and visceral adipose tissue: their relation to the metabolic syndrome. Endocr Rev. 2000;21:697-738.

29. Despres JP, Lemieux I, Prud'homme D. Treatment of obesity: need to focus on high risk abdominally obese patients. BMJ. 2001;322:716-20.

30. Clinical Guidelines on the Identification, Evaluation, and Treatment of Overweight and Obesity in Adults. The Practical Guide. Rockville, MD:

National Institutes of Health, U.S. Department of Health and Human Services; October 2000. NIH Publication No. 00-4084.

31. Bariatric surgery statistics. Available at: http://www.bariatric-surgery.info/ statistics.htm. Accessed November 7, 2005.

32. Centers for Disease Control and Prevention. Physical activity and health: a report of the Surgeon General. Atlanta, GA; 1996. Available at: http://www.cdc.gov/nccdphp/sgr/sgr.htm. Accessed December 5, 2005.

33. Centers for Disease Control and Prevention. U.S. physical activity statistics: 1986-2002. No leisure-time physical activity trend chart. Available at: http://www.cdc.gov/nccdphp/dnpa/physical/stats/leisure_time.htm. Accessed November 2, 2005

34. The Institute of Medicine. Dietary Reference Intakes for Energy, Carbohydrate, Fiber, Fat, Fatty Acids, Cholesterol, Protein, and Amino Acids. Washington, DC: Institute of Medicine; 2002.

35. Wirth A, Krause J. Long-term weight loss with sibutramine: a randomized controlled trial. JAMA. 2001;286:1331-39.

36. Lutz B. Molecular biology of cannabinoid receptors. Prostaglandins Leukot Essent Fatty Acids. 2002;66:123-42.

37. Grotenhermen F. Cannabinoids. Curr Drug Targets CNS Neurol Disord. 2005:4:507-30.

38. Van Gaal LF, Rissanen AM, Scheen AJ, Ziegler O, Rossner S; RIO-Europe Study Group. Effects of the cannabinoid-1 receptor blocker rimonabant on weight reduction and cardiovascular risk factors in overweight patients: 1-year experience from the RIO-Europe study. Lancet. 2005;365:1389-97.

39. Pi-Sunyer FX. Effect of rimonabant on weight reduction and weight maintenance: RIO-North America (RIO-NA) trial. Paper presented at: American Heart Association Scientific Sessions; November 9, 2004; New Orleans, LA. 40. Robins SJ, Collins D, Wittes JT, et al. Relation of gemfibrozil treatment and lipid levels with major coronary events: VA-HIT: a randomized controlled trial. JAMA. 2001;285:1585-91.

41. Medical College of Wisconsin. Diabetes and heart disease: the diabetes epidemic. Available at: http://healthlink.mcw.edu/article/980799269.html. Accessed December 1, 2005.

42. Greenbaum CJ, Kahn SE, Palmer JP. Nicotinamide's effects on glucose metabolism in subjects at risk for IDDM. Diabetes. 1996;45:1631-34. 43. Despres JP, Golay A, Sjorstrom L, Rimonabant, for the Obesity-Lipids Study Group. Effects of rimonabant on metabolic risk factors in overweight patients with dyslipidemia. N Engl J Med. 2005;353(20):2121-34.

44. Després J-P. Weight reducing and metabolic effects in overweight/obese patients with dyslipidemia RIO-lipids trial. late-breaking clinical trials II. Paper presented at: America College of Cardiology 53rd Annual Scientific Session; March 7-10, 2004; New Orleans, LA.

45. Scheen A. Late-breaking abstracts. Program and abstracts of the 65 th Scientific Sessions of the American Diabetes Association; June 10-14, 2005; San Diego, CA. 